\title{
Serum concentrations of 25-hydroxyvitamin D and different subtypes of age-related cataract; a case- control study
}

\author{
Naser Samadi Aidenloo* ${ }^{\circledR}$, Qader Motarjemizadeh* ${ }^{\circledR}$, Sanaz Moradi Nahriq \\ Department of Ophthalmology, Urmia University of Medical Sciences, Urmia, Iran
}

\section{*Correspondence to \\ Naser Samadi Aidenloo, Email: nasersamadiseye@ gmail.com, samadi.i@umsu. ac.ir; \\ Qader Motarjemizadeh \\ Emial: \\ motarjemizadeh.q@umsu.ac.ir}

Received 14 Oct. 2020 Accepted 3 Feb. 2021

Published online 22 Feb. 2021

Keywords: Vitamin D, 25-hydroxyvitamin D, 25(OH) $\mathrm{D}$, Age related cataract

\begin{abstract}
Introduction: Age-related cataract (ARC) is the principal causes of low vision and also the most prevalent type of cataract among the elderly population, particularly women.

Objectives: To evaluate the association between serum concentration of vitamin D and risk of different subtypes of senile cataract.

Patients and Methods: A total of 200 controls and 1241 patients with newly recognized ARC attending the ophthalmology ward of a major teaching hospital in Urmia, Iran, were included in this investigation. All included subjects aged 40 to 85 years. Cataracts were classified as pure nuclear cataract $(\mathrm{NC})(\mathrm{n}=216)$, pure cortical cataract (CC) $(n=336)$, pure posterior sub-capsular cataract (PSC) $(n=140)$ and mixed cataracts (549). Serum concentration of 25-hydroxyvitamin D was obtained from blood samples. All participants were administered by a questionnaires to collect data on demographic variables and risk factors.

Results: On multivariate analysis, a marked negative association $(P<0.05)$ was found between vitamin $\mathrm{D}$ serum levels and the risk of $\mathrm{NC}(\mathrm{OR}=0.20 ; 95 \% \mathrm{Cl}: 0.09-0.75)$ or $\mathrm{CC}(\mathrm{OR}=0.25 ; 95 \% \mathrm{Cl}: 0.12-0.96)$ in females only. Other significant predictors of pure $N C$ in women were higher education $(O R=0.51)$ and serum calcium levels $(O R=0.35)$. Apart from serum concentrations of vitamin $D$, postmenopausal status $(O R=2.26)$ was the other predisposing factor for pure cortical opacity in women.

Conclusion: Our finding does not endorse a role for vitamin D in cataractogenesis among men. In women, however, serum levels of 25(OH)D were only inversely associated with the risk of NC and CC and not with PSC or mixed cataract. Providing sufficient vitamin D is possibly helpful in preventing senile cataract formation in females.
\end{abstract}

Citation: Samadi
Aidenloo N,
Motarjemizadeh Q,
Moradi Nahriq S.
Serum concentrations
of 25-hydroxyvitamin
D and different
subtypes of age-related
cataract; a case-control
study. Immunopathol
Persa. 2022;8(1):e16.
DOI:10.34172/
ipp.2022.16.

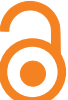

\section{Introduction}

Cataract can be defined as clouding or opacification of the ocular lens that obstacle the passage of light (1). Senile cataract or agerelated cataract (ARC) is the principal causes of low vision and blindness worldwide (2). ARC is also the most prevalent type of cataract among the elderly population and particularly women (3). The augmented oxidation of polypeptides or lipids within the lens is hypothesized to be involved in the development of ARC (4). The frequency of individuals affected by senile cataract is expected to rise sharply during the next 20 years due to the growing proportion of elderly persons in most countries (5). Surgical extraction of cloudy lens is the only available treatment for ARC. However, economic problems are challenges for patients. It has been estimated that a 10-year delay in age of onset could decrease the necessity of surgery by $50 \%$, remarkably reducing medical costs (6). Thus, identifying modifiable risk

\begin{abstract}
Key point
In our study, we found vitamin D has no main role in cataractogenesis among men. In women, however, serum levels of $25(\mathrm{OH}) \mathrm{D}$ were only inversely associated with the risk of pure nuclear and pure cortical cataract, however it was not associated with pure posterior subcapsular or mixed cataracts.
\end{abstract}

factors of lens opacities in the elderly is essential to establish preventive measures for ARC. Unhealthy lifestyles that can increase oxidative stress and inflammation such as smoking (7), obesity (8-9), low phytochemical intake (10), alcohol use (11), and low levels of physical activity (12) are among the modifiable risk factors for ARC. There are three main types of senile cataract depending on the location of the opacity within the lens; nuclear cataract (NC), cortical cataract (CC), and posterior subcapsular cataract (PSC) (13). Each of these

Copyright (C) 2022 The Author(s); Published by Nickan Research Institute. This is an open-access article distributed under the terms of the Creative Commons Attribution License (http://creativecommons.org/licenses/by/4.0), which permits unrestricted use, distribution, and reproduction in any medium, provided the original work is properly cited. 
conditions may occur alone or combined with one or both of the other types (i.e. mixed cataract). However, it is now quite evident that various types of ARC have different age of onset and distinct pathology. They also seem to have divergent risk factors (14).

While first identified for its role as a modulator of calcium homeostasis and metabolism, vitamin $\mathrm{D}$ is now known to possess multiple functions, including involvement in cell proliferation and differentiation, regulation of immune system, apoptosis, angiogenesis and oxidative status of cells $(15,16)$. Numerous research works have demonstrated a protective role of vitamin $\mathrm{D}$ against chronic diseases such as cardiovascular disease, diabetes mellitus, multiple sclerosis, schizophrenia, rheumatoid arthritis, and neoplastic disease (17). Additionally, a growing body of experimental evidence has shown that vitamin $\mathrm{D}$ may be beneficial in preventing a broad spectrum of ocular disorders such as glaucoma (18), myopia (19), diabetic retinopathy (20), and age-related macular degeneration (21). Few previous investigations have also observed a significant association between reduced serum levels of vitamin D and elevated risk of senile cataract $(22,23), \mathrm{CC}$ (24), NC $(25,26)$, and PSC (27).

There are two sources of vitamin D: dietary consumption and formation in the skin through exposure to sunlight. Vitamin D production in the skin varies with the amount of clothing worn, time spent outside, season of the year, cloud cover as well as skin pigmentation (28). Moreover, endogenous synthesis of vitamin D in human skin depends on the incident angle of the sun. On the other hand, prior studies have demonstrated that exposure to solar radiation induces lens opacification. Hence, the relationship between vitamin $\mathrm{D}$ levels in the body and opacity formation in the lense cells might differ in different parts of the earth because of the influences of latitude, culture, and protective measures used by people against sunlight such as sunscreen creams, exposureblocking clothing, sunglasses, and hats. Since, multiple frequent polymorphisms have been recognized in the genes of vitamin D receptors (29), the possibility of a genetic susceptibility to cataract development could not be entirely excluded (22). All of these warrant further attempts to elucidate vitamin D's role in senile cataract among different ethnicities with different cultures, genetic backgrounds, life styles and habitats.

\section{Objectives}

The current investigation was designed to examine whether there is an association between serum 25-hydroxy vitamin $\mathrm{D}$ levels and different subtypes of ARC in a representative Iranian population.

\section{Patients and Methods}

\section{Study design}

The subjects were 1241 sporadic patients with ARCs and 200 normal controls who were recruited during the spring and summer seasons between April 2015 and August 2017. In total, 216 cases (17.4\%) had NC, 336 (27.1\%) had CC, 140 (11.3\%) had PSC, and 549 (44.2\%) had mixed cataract. Mixed cortical and nuclear opacities were found in 45 female subjects, mixed cortical and PSC cataracts in 76 , mixed nuclear and posterior subcapsular opacities in 57 , and 87 women had all three types of cataract. The male mixed group consisted of the following subgroups: cortical and nuclear, 56; cortical and PSC, 72; nuclear and PSC, 54; and nuclear, cortical, and PSC, 102. All participants were unrelated Iranian, seen in a principal referral center in Northwest Iran (Imam hospital), with at least 5 years residence in Urmia (the capital city of the West Azarbaijan province, $37^{\circ} 33^{\prime} 19^{\prime \prime} \mathrm{N} 45^{\circ} 04^{\prime} 21^{\prime \prime} \mathrm{E}$ ). Exclusion criteria included history of other ocular surgery or ocular trauma, persistent intraocular inflammation, uveitis, glaucoma, systemic vasculitis, high myopia, hyper/ hypothyroidism, hyper/hypoparathyroidism, preexisting liver or kidney disorders and degenerated ocular diseases. Patients taking calcium and vitamin D supplements at the time of admission were excluded as well. It was attempted to include subjects with no sign of cataract in the control arm, as much as possible. However, as it was difficult to find such individuals in the older age groups, some control participants had lens opacity in an early form. Controls were age-matched individuals who attended the same health care institution for standard ophthalmic medical checkups. They had no history of cataract surgery and lacked other ocular abnormalities except for refractive disorders. All investigated subjects received baseline ocular assessments in addition to completing a general health and lifestyle questionnaire. Information on prevalent medical conditions, medications (e.g. anti-hypertensive and antihyperglycemic drugs), smoking status (never, current, past), and average daily sunlight exposure were obtained by this questionnaire. Blood pressure was measured in the sitting position after 5 min rest. Diabetics were recognized as those with fasting blood sugar levels higher than $126 \mathrm{mg} / \mathrm{dL}$ or individuals who were using insulin or oral hypoglycemic agents. Hypertensive cases were defined as those with systolic/diastolic blood pressures higher than 140/90 $\mathrm{mm} \mathrm{Hg}$ or subjects who were using antihypertensive medications. Height and weight were measured with the subjects wearing light clothing and body mass index (BMI) was calculated as mass (kg) divided by standing height $\left(\mathrm{m}^{2}\right)$. Baseline ocular assessment included ophthalmoscopic examination, visual acuity, and lens examination in transient and side illumination with a slit lamp biomicroscopy after pupil dilatation induced with tropicamide $0.5 \%$ and phenylephrine $10 \%$ drops. A quantitative assessment of opacities was achieved using slit lamp illumination technique according to the standard Lens Opacities Classification Systems III (LOCS III) (30). Opacities were compared with standard photographs and subtypes of cataract were defined as pure nuclear (LOCS III score $\geq 3$ for nuclear opalescence or nuclear color), pure 
cortical (LOCS III score $\geq 2$ for cortical cataract), pure posterior subcapsular (LOCS III score $\geq 2$ for posterior subcapsular cataract) and mixed cataract (more than one subtype per eye). Final diagnostic classification was determined by consensus of two ophthalmologists (NSA and QM). Only those patients that had a single subtype of cataract in both eyes and a single subtype of cataract in one eye and no opacities in the other eye in the same person were included in the pure groups. Mixed cataract was defined as the presence of a combination of any two type of opacity. Only data for the worse lens of each patient were included in the study.

\section{Serum assays}

Serum concentration of $25(\mathrm{OH}) \mathrm{D}$ was measured in this investigation, as it is extensively recognized as the preferred biomarker for vitamin D status in the body and manifests not only its dietary intake but also its cutaneous production (31). Serum samples were collected following overnight fasting and transferred to a $-80^{\circ} \mathrm{C}$ freezer until the time of testing. A chemiluminescent immunoassay kit (25 OH Vitamin D total assay, DiaSorin Liaison ${ }^{\circledR}$ ) and LIAISON analyzer were utilized to measure the total level of serum 25(OH)D. The criterion of World Health Organization (32) was used to categorize serum 25(OH)D levels in this study (less than $20 \mathrm{ng} / \mathrm{mL}$ as deficiency, 20-29 $\mathrm{ng} / \mathrm{mL}$ as insufficiency, and above $30 \mathrm{ng} / \mathrm{mL}$ as optimal). Participants' sugar profiles were measured by standard enzymatic assays (Pars Azmoon, Diagnostic Kits, Iran). A Biosource kit (Biosource Europe S.A; normal range: 13$66 \mathrm{pg} / \mathrm{mL}$ ) was used for detection of serum parathyroid hormone (PTH). Serum concentration of calcium was measured by colorimetry using the Kavoshyar enzyme kit (Kavoshyar, Diagnostic Kits, Iran).

\section{Statistical analysis}

Continuous variables were presented as mean \pm standard deviation (SD) and were compared by two-tailed Student's $t$ test, whereas categorical variables were compared using chi-square test. Logistic regression analyses were fitted to examine the cross-sectional association between vitamin D status and different types of ARC. Mantel-Haenszel statistic and multinomial logistic regression analysis were used to estimate odds of lens opacity by categorical and continuous parameters, respectively, after controlling for age and serum levels of 25(OH)D. Moreover, the univariate analysis was applied to estimate the association of serum vitamin D levels with other variables. For this purpose, we computed Pearson's correlation coefficients to evaluate the relationships between continuous variables and vitamin $\mathrm{D}$ concentrations. Student's $t$ test was also used to compare the mean values of vitamin $\mathrm{D}$ in dichotomous variables. Subsequently, in order to determine independent predictors of serum concentration of vitamin $\mathrm{D}$, a multiple linear regression analysis was conducted to further analyze significantly associated variables. Statistical analyses were performed using SPSS version 22 and STATA version 12.1 . A probability value $<0.05$ was used to establish statistical significance.

\section{Results}

Baseline characteristics of the controls and different types of ARC are summarized in Tables 1 and 2 for males and females, respectively. Since the average concentrations of vitamin $\mathrm{D}$ were significantly different between males and females in almost all subgroups, the analysis was stratified according to gender to inspect the interaction of gender with serum 25-hydroxyvitamin D levels. Nuclear cataract was the only subgroup in which no significant difference was found between men and women in terms of the average concentration of serum $25(\mathrm{OH}) \mathrm{D}$. Individuals with NC in both genders (Student $t$ test, $P=0.012$ and $\mathrm{P}$ $=0.027$ for men and women, respectively) and women with CC (Student $t$ test $P=0.008$ ) had lower serum 25-hydroxyvitamin D levels compared to the controls (Tables 1 and 2). Conversely, men with CC had higher albeit statistically non-significant serum 25-hydroxyvitamin D levels compared to male controls (Student $t$ test $P=0.061$; Table 1). The chi-square findings also unveiled that the frequency of vitamin D-deficient women with $\mathrm{NC}$ and CC ( $P=0.007$ and $P=0.022$, respectively) and number of vitamin $\mathrm{D}$-deficient men with $\mathrm{NC}(P=0.025)$ were more than controls (Tables 1 and 2). In addition, male patients with NC and CC had longer daily sun exposure times compared with male controls (Student $t$ test, $P=0.031$ and $P=0.011$, respectively; Table 1 ). On the contrary, the average time exposure to solar radiation per day was shorter in female patients with nuclear $(P=0.024)$ and cortical opacities $(P=0.017)$ than women controls (Table 2).

Table 3 provides the results of two logistic regression models examining the cross-sectional association between vitamin D deficiency and different subtypes of ARC according to gender. Age-adjusted model demonstrated that vitamin $\mathrm{D}$ deficiency (i.e., serum $25(\mathrm{OH}) \mathrm{D}<20$ $\mathrm{ng} / \mathrm{mL}$ ) was markedly associated with increased odds of almost all subtypes of ARC except for the mixed cataract in female cases. Meanwhile, the odds of having pure nuclear cataract increased by a factor of 3.15 for males suffered from vitamin D deficiency after adjustment for age ( $P=0.025$; Table 3$)$. However, the fully adjusted model unveiled that the vitamin $\mathrm{D}$ deficiency remained an independent predictor of only NC in women (odds ratio $[\mathrm{OR}]=4.06,95 \%$ confidence interval $[\mathrm{CI}]=1.58$ $15.26, P=0.002)$. Another logistic regression analysis was conducted to evaluate the independent effect of serum 25(OH)D concentration on ARC development (Table 4). Among different subtypes of senile cataract, serum $25(\mathrm{OH}) \mathrm{D}$ concentration was only associated with $\mathrm{NC}$ and $\mathrm{CC}$ in women after adjustment for all confounding factors (Table 4, model 2).

In order to control the effect of age and serum vitamin 
Table 1. Demographic and clinical characteristics of male subjects in different age-related cataract groups and controls

\begin{tabular}{|c|c|c|c|c|c|}
\hline \multirow[b]{2}{*}{ Demographic characteristics } & \multicolumn{4}{|c|}{ Type of age-related cataract $(n=636)$} & \multirow[b]{2}{*}{ Controls $(n=100)$} \\
\hline & Pure nuclear $(n=113)$ & $\begin{array}{l}\text { Pure cortical } \\
\quad(n=171)\end{array}$ & $\begin{array}{l}\text { Pure posterior sub- } \\
\text { capsular }(\mathrm{n}=68)\end{array}$ & Mixed $(n=284)$ & \\
\hline \multicolumn{6}{|l|}{ Age $(y)$} \\
\hline Range & $40-82$ & $41-77$ & $42-77$ & $41-84$ & $40-76$ \\
\hline Median & 67 & 65 & 66 & 62 & 63 \\
\hline Mean & $65.9(8.6)^{\mathrm{a}}$ & $64.1(7.9)$ & $64.5(8.5)$ & $60.3(8.8)$ & $62.1(8.2)$ \\
\hline $\mathrm{BMI}\left(\mathrm{kg} / \mathrm{m}^{2}\right)$ & $26.7(3.4)^{\mathrm{a}}$ & $25.2(3.2)$ & $25.7(3.2)$ & $26.2(3.5)^{\mathrm{a}}$ & $24.3(3.2)$ \\
\hline Hypertension & $29(25.7)$ & $75(43.9)^{a}$ & $14(20.6)$ & $68(23.9)$ & $26(26.0)$ \\
\hline Diabetes & $23(20.4)$ & $49(28.7)$ & $26(38.2)^{\mathrm{a}}$ & $73(25.7)$ & $22(22.0)$ \\
\hline \multicolumn{6}{|l|}{ Smokers } \\
\hline Never & $82(72.6)$ & $129(75.4)$ & $48(70.6)$ & $193(68.0)^{c}$ & $81(81.0)$ \\
\hline Past & $5(4.4)$ & $12(7.0)$ & $6(8.8)$ & $26(9.2)$ & $7(7.0)$ \\
\hline Current & $26(23.0)^{\mathrm{a}}$ & $30(17.5)$ & $14(20.6)$ & $65(22.9)^{c}$ & $12(12.0)$ \\
\hline \multicolumn{6}{|l|}{ Education } \\
\hline Illiterate & $29(25.7)$ & $42(24.6)$ & $11(16.2)$ & $63(22.2)$ & $24(24.0)$ \\
\hline School & $71(62.8)$ & $103(60.3)$ & $42(61.8)$ & $175(61.6)$ & $56(56.0)$ \\
\hline University & $13(11.5)$ & $26(15.2)$ & $15(22.1)$ & $46(16.2)$ & $20(20.0)$ \\
\hline Serum vitamin $\mathrm{D}(\mathrm{ng} / \mathrm{mL})$ & $26.1(8.2)^{d}$ & $40.3(8.7)$ & $32.3(7.9)$ & $34.1(8.8)$ & $36.2(8.4)$ \\
\hline \multicolumn{6}{|l|}{ Vitamin D } \\
\hline Normal (>30 ng/mL) & $33(29.2) \dagger$ & $86(50.3)$ & $25(36.8)$ & $101(35.6)$ & $46(46.0)$ \\
\hline Insufficiency (20-30 ng/mL) & $26(23.0)$ & $45(26.3)$ & $20(29.4)$ & $72(25.3)$ & $22(22.0)$ \\
\hline Deficiency $(<20 \mathrm{ng} / \mathrm{mL})$ & $54(47.8)^{\mathrm{a}}$ & $40(23.4)$ & $23(33.8)$ & $111(39.1)$ & $32(32.0)$ \\
\hline Calcium (mg/dL) & $9.3(0.7)$ & $9.5(0.6)$ & $9.4(0.8)$ & $9.6(0.5)$ & $9.7(0.6)$ \\
\hline PTH $(\rho g / m L)$ & $42.3(13.2)^{b}$ & $30.4(11.9)$ & $35.6(13.4)$ & $35.2(12.1)$ & $33.3(9.4)$ \\
\hline Sun exposure time/day [hour] & $3.09(1.6)^{\mathrm{a}}$ & $3.38(1.7)^{\mathrm{a}}$ & $2.52(1.6)$ & $2.61(1.6)$ & $2.48(1.6)$ \\
\hline
\end{tabular}

Abbreviations: 25(OH)D, 25-hydroxy vitamin D; BMI, body mass index; SD, standard deviation.

Categorical and continuous variables are presented as number (\%) and mean (SD), respectively.

Chi-square and Student $t$ tests were respectively utilized to compare categorical and continuous variables between different subtypes of senile cataract and control group

a Significantly higher than control group at $P<0.05$ level; ${ }^{\mathrm{b}}$ Significantly higher than control group at $P<0.01$ level; ${ }^{\mathrm{c}}$ Significantly lower than control group at $P$ $<0.05$ level; ${ }^{\text {d }}$ Significantly lower than control group at $P<0.01$ level.

D levels and see the independent associations of various medical and demographic parameters with different subtypes of ARC, we computed Mantel-Haenszel statistics for categorical variables and developed multinomial logistic regression analyses for continuous factors (Table 5). The results revealed that apart from vitamin $\mathrm{D}$, higher education and elevated concentrations of serum calcium were inversely associated with risk of NC in women (OR $=0.51$ and $\mathrm{OR}=0.35$, respectively; Table 5 ). It was also found that menopausal women had an increased risk of $\mathrm{CC}(\mathrm{OR}=2.26,95 \% \mathrm{CI}: 1.46-4.21)$. On the other hand, sun exposure time was the most powerful determinant of cortical $(\mathrm{OR}=2.48,95 \% \mathrm{CI}=1.21-5.75)$ and nuclear $(\mathrm{OR}=2.08,95 \% \mathrm{CI}=1.31-3.95)$ opacities in male cases (Table 5).

A stepwise multiple linear regression analysis was achieved to determine independent predictors of serum $25(\mathrm{OH}) \mathrm{D}$ levels in different subtypes of senile cataract (Table 6). Hypertension and age were the strongest independent predictors of vitamin D levels in females with $\mathrm{NC}$ and CC, respectively.

\section{Discussion}

Our analysis demonstrated that women with vitamin D deficiency (i.e. serum $25(\mathrm{OH}) \mathrm{D}<20 \mathrm{ng} / \mathrm{mL}$ ) were 2.5 times more likely to suffer from cortical cataract than females with adequate vitamin D status. However, the 95\% $\mathrm{CI}$ of this association did not show statistical significance after adjusting for confounders. At the same time, the risks of nuclear opacity increased up to 4 times in females with vitamin $\mathrm{D}$ deficiency relative to women with adequate vitamin D status. Unlike the risk of cortical cataract in females, this association remained significant even after additional controlling for covariates.

The findings of the present study also revealed that females with cortical cataract had lower mean levels of serum $25(\mathrm{OH}) \mathrm{D}$ relative to the control females. A significant difference was not observed, however, between men with pure cortical opacity and male controls. Postadjustment analysis suggested that the inverse association between vitamin $\mathrm{D}$ and cortical opacity remained significant in women, but the interaction term was of borderline significance $(P<0.044$; Table 4$)$. Unlike 
Table 2. Demographic and clinical characteristics of female subjects in different age-related cataract groups and controls

\begin{tabular}{|c|c|c|c|c|c|}
\hline \multirow[b]{2}{*}{ Demographic characteristics } & \multicolumn{4}{|c|}{ Type of age-related cataract [ $n=605]$} & \multirow[b]{2}{*}{ Controls $(n=100)$} \\
\hline & Pure nuclear $(n=103)$ & Pure cortical ( $n=165)$ & $\begin{array}{c}\text { Pure posterior sub- } \\
\text { capsular }(n=72)\end{array}$ & Mixed $(n=265)$ & \\
\hline \multicolumn{6}{|l|}{ Age } \\
\hline Range & $40-85$ & $42-76$ & $40-81$ & $41-79$ & $40-79$ \\
\hline Median & 68 & 65 & 63 & 65 & 63 \\
\hline Mean & $66.9(8.6)$ & $64.7(7.4)$ & $62.3(8.2)$ & $64.5(9.0)$ & $63.1(7.8)$ \\
\hline BMI $\left(\mathrm{kg} / \mathrm{m}^{2}\right)$ & $25.7(3.3)$ & $24.8(3.7)$ & $25.5(3.2)$ & $26.3(3.5)^{\mathrm{a}}$ & $24.1(3.6)$ \\
\hline Hypertension & $25(24.3)$ & $42(25.5)$ & $17(23.6)$ & $75(28.3)$ & $23(23.0)$ \\
\hline Diabetes & $22(21.4)$ & $39(23.6)$ & $24(33.3)^{\mathrm{a}}$ & $67(25.3)$ & $19(19.0)$ \\
\hline \multicolumn{6}{|l|}{ Smokers } \\
\hline Never & $93(90.3)$ & $153(92.7)$ & $68(94.4)$ & $250(94.3)$ & $95(95)$ \\
\hline Past & $10(9.7)$ & $10(6.1)$ & $4(5.6)$ & $10(3.8)$ & $5(5)$ \\
\hline Current & 0 & $2(1.2)$ & 0 & $5(1.9)$ & 0 \\
\hline \multicolumn{6}{|l|}{ Education } \\
\hline Illiterate & $33(32.0)$ & $56(33.9)$ & $21(29.2)$ & $85(32.1)$ & $33(33.0)$ \\
\hline School & $53(51.5)$ & $99(60.0)$ & $46(63.9)$ & $139(52.4)$ & $61(61.0)$ \\
\hline University & $17(16.5)^{\mathrm{a}}$ & $10(6.1)$ & $5(6.9)$ & $41(15.5) \dagger$ & $6(6.0)$ \\
\hline Serum vitamin D [ng/mL] & $24.2(7.7)^{\mathrm{d}}$ & $24.1(8.2)+t$ & $27.8(8.6)$ & $28.0(8.1)$ & $32.7(8.2)$ \\
\hline \multicolumn{6}{|l|}{ Vitamin D } \\
\hline Normal (>30 ng/mL) & $23(22.3)^{c}$ & $52(31.5)$ & $23(31.9)$ & $102(38.5)$ & $39(39.0)$ \\
\hline Insufficiency (20-30 ng/mL) & $24(23.3)$ & $31(18.8)$ & $17(23.6)$ & $53(20.0)$ & $26(26.0)$ \\
\hline Deficiency $(<20$ ng/mL) & $56(54.4)^{b}$ & $82(49.7)^{\mathrm{a}}$ & $32(44.4)$ & $110(41.5)$ & $35(35.0)$ \\
\hline Calcium (mg/dL) & $8.9(0.6)$ & $8.5(0.5)^{c}$ & $9.4(0.8)$ & $9.6(0.5)$ & $9.9(0.6)$ \\
\hline PTH $(\rho g / m l)$ & $45.3(13.1)^{\mathrm{b}}$ & $45.4(12.9)^{\mathrm{b}}$ & $42.6(13.1)^{\mathrm{a}}$ & $35.2(12.4)$ & $36.3(10.1)$ \\
\hline Sun exposure time/day (hour) & $1.15(1.3)^{\mathrm{c}}$ & $1.11(1.3)^{\mathrm{c}}$ & $1.82(1.2)$ & $1.62(1.2)$ & $1.70(1.2)$ \\
\hline Postmenopausal & 87 (84.5) & 112 (67.9) & $47(65.3)$ & $203(76.6)^{a}$ & $66(66.0)$ \\
\hline \multicolumn{6}{|l|}{ Number of children } \\
\hline 0 & $3(2.9)$ & $5(3.0)$ & 0 & $6(2.3)$ & $2(2.0)$ \\
\hline $1-3$ & 55 (53.4) & $91(55.2)$ & 37 (51.4) & $161(60.8)$ & $58(58.0)$ \\
\hline $4-6$ & $42(40.8)$ & $61(37.0)$ & $32(44.4)$ & $85(32.1)$ & $37(37.0)$ \\
\hline$\geq 7$ & $3(2.9)$ & $8(4.8)$ & $3(4.2)$ & $13(4.9)$ & $3(3.0)$ \\
\hline$>3$ & $45(43.7)$ & $69(41.8)$ & 35 (48.6) & $98(37.0)$ & $40(40.0)$ \\
\hline
\end{tabular}

Abbreviations: 25(OH)D, 25-hydroxy vitamin D; BMI, body mass index; SD, standard deviation.

Categorical and continuous variables are presented as number (\%) and mean (SD), respectively. Chi-square and Student $t$ tests were respectively utilized to compare categorical and continuous variables between different subtypes of senile cataract and control group.

a Significantly higher than control group at $P<0.05$ level; ${ }^{\text {b }}$ Significantly higher than control group at $P<0.01$ level; ${ }^{\text {c }}$ Significantly lower than control group at $P$

$<0.05$ level; ${ }^{\text {d }}$ Significantly lower than control group at $P<0.01$ level.

Table 3. Logistic regression models examining the cross-sectional association between vitamin D deficiency and different subtypes of age-related cataract

\begin{tabular}{|c|c|c|c|c|c|}
\hline \multirow{3}{*}{ Types of age-related cataract } & \multirow{3}{*}{ Gender } & \multicolumn{4}{|c|}{ Vitamin D deficiency $[25(\mathrm{OH}) \mathrm{D}<20 \mathrm{ng} / \mathrm{mL}]$} \\
\hline & & \multicolumn{2}{|c|}{ Model $1^{a}$} & \multicolumn{2}{|c|}{ Model $2^{b}$} \\
\hline & & Adjusted OR $[95 \% \mathrm{Cl}]$ & $P$ value & Adjusted OR $[95 \% \mathrm{CI}]$ & $P$ value \\
\hline \multirow{2}{*}{ Pure Nuclear } & Men & $3.15[1.27-5.25]$ & 0.025 & $1.53[0.76-4.92]$ & 0.121 \\
\hline & Women & $4.14[1.84-7.35]$ & 0.007 & $4.06[1.58-15.26]$ & 0.002 \\
\hline \multirow{2}{*}{ Pure Cortical } & Men & $1.12[0.77-3.86]$ & 0.431 & $0.94[0.34-2.32]$ & 0.259 \\
\hline & Women & $2.50[1.62-3.96]$ & 0.031 & $1.42[0.65-2.37]$ & 0.079 \\
\hline \multirow{2}{*}{ Pure Posterior Sub-capsular } & Men & $2.22[0.52-11.67]$ & 0.651 & $1.06[0.30-12.33]$ & 0.669 \\
\hline & Women & $3.11[1.13-17.94]$ & 0.036 & $2.44[0.47-24.68]$ & 0.376 \\
\hline \multirow{2}{*}{ Mixed Cataract } & Men & $1.75[0.46-3.78]$ & 0.661 & $1.52[0.66-2.88]$ & 0.421 \\
\hline & Women & 2.19 [0.51-3.65] & 0.531 & $1.74[0.72-2.36]$ & 0.317 \\
\hline
\end{tabular}

Abbreviations: $\mathrm{OR}$, odds ratio; $\mathrm{Cl}$, confidence interval.

a Adjusted for age.

${ }^{\mathrm{b}}$ Adjusted for age, body mass index, education, diabetes mellitus, hypertension, smoking status, daily sun exposure and menopausal status and childbearing $>3$ for women. 
Table 4. Association between serum concentrations of vitamin D with risk of different subtypes of age-related cataract according to gender

\begin{tabular}{|c|c|c|c|c|c|}
\hline \multirow{3}{*}{ Types of age-related cataract } & \multirow{3}{*}{ Gender } & \multicolumn{4}{|c|}{ 25-Hydroxyvitamin D } \\
\hline & & \multicolumn{2}{|c|}{ Model 1 ${ }^{\mathrm{a}}$} & \multicolumn{2}{|c|}{ Model $2^{b}$} \\
\hline & & Adjusted OR [95\% CI] & $P$ value & Adjusted OR [95\% CI] & $P$ value \\
\hline \multirow{2}{*}{ Pure Nuclear } & Men & $0.25[0.11-0.86]$ & 0.015 & $0.65[0.21-2.25]$ & 0.251 \\
\hline & Women & $0.31[0.14-0.85]$ & $<0.001$ & $0.20[0.09-0.75]$ & 0.008 \\
\hline \multirow{2}{*}{ Pure Cortical } & Men & $0.72[0.57-1.86]$ & 0.627 & $0.92[0.77-2.86]$ & 0.720 \\
\hline & Women & $0.48[0.18-0.89]$ & 0.006 & $0.25[0.12-0.96]$ & 0.044 \\
\hline \multirow{2}{*}{ Pure Posterior Sub-capsular } & Men & $1.22[0.72-8.67]$ & 0.681 & $0.81[0.22-8.67]$ & 0.843 \\
\hline & Women & $0.41[0.12-7.14]$ & 0.086 & $0.76[0.33-11.94]$ & 0.176 \\
\hline \multirow{2}{*}{ Mixed Cataract } & Men & $1.75[0.47-3.78]$ & 0.317 & $1.48[0.16-5.99]$ & 0.268 \\
\hline & Women & $0.69[0.31-2.05]$ & 0.491 & $0.91[0.51-2.25]$ & 0.305 \\
\hline
\end{tabular}

Abbreviations: OR, odds ratio; $\mathrm{Cl}$, confidence interval.

a Adjusted for age.

${ }^{\mathrm{b}}$ Adjusted for age, body mass index, education, diabetes mellitus, hypertension, smoking status, daily sun exposure and menopausal status and childbearing $>3$ for women.

Table 5. Age and vitamin D-adjusted odds of opacity based on Mantel-Haenszel statistic or multinomial logistic regression analysis according to gender

\begin{tabular}{|c|c|c|c|c|c|}
\hline & & \multicolumn{4}{|c|}{ Types of age-related cataract } \\
\hline & & Pure Nuclear & Pure Cortical & Pure Posterior Sub-capsular & Mixed \\
\hline \multirow{8}{*}{ Men } & BMI & $1.55[1.03-3.18]$ & $1.48[0.71-4.11]$ & $2.75[1.42-8.13]$ & $1.71[1.03-2.58]$ \\
\hline & Hypertension & $0.76[0.54-1.36]$ & $2.16[1.82-6.42]$ & $0.91[0.37-2.71]$ & $1.16[0.52-1.42]$ \\
\hline & Diabetes & $1.47[0.28-2.18]$ & $0.75[0.23-2.38]$ & $3.79[1.43-9.78]$ & $1.45[0.59-2.39]$ \\
\hline & Current smoking & $1.70[1.17-3.96]$ & $1.37[0.15-2.39]$ & $1.48[0.17-5.90]$ & $2.09[1.14-3.16]$ \\
\hline & Higher education & $0.76[0.34-1.72]$ & $0.43[0.23-1.58]$ & $0.61[0.41-3.73]$ & $0.53[0.14-1.05]$ \\
\hline & Calcium & $0.43[0.16-1.78]$ & $0.82[0.41-1.68]$ & $1.09[0.26-2.69]$ & $0.75[0.55-1.76]$ \\
\hline & PTH & $1.36[0.41-1.58]$ & $1.87[0.58-3.34]$ & $2.46[0.95-5.02]$ & 1.19 [0.63-1.98] \\
\hline & Sun exposure time & $2.08[1.31-3.95]$ & $2.48[1.21-5.75]$ & $1.18[0.50-8.85]$ & $2.14[0.77-3.75]$ \\
\hline \multirow{9}{*}{ Women } & BMI & $1.59[0.35-3.29]$ & $1.48[0.51-3.76]$ & $0.89[0.15-6.09]$ & $2.35[1.25-4.69]$ \\
\hline & Hypertension & $1.63[0.28-2.66]$ & $1.83[0.30-2.48]$ & $1.47[0.41-5.30]$ & $0.93[0.13-1.52]$ \\
\hline & Diabetes & $1.71[0.43-3.63]$ & $1.58[0.38-2.99]$ & $1.88[1.31-4.23]$ & $1.23[0.73-2.96]$ \\
\hline & Higher education & $0.51[0.21-0.97]$ & $1.29[0.42-8.32]$ & $0.93[0.26-9.97]$ & $0.61[0.16-0.99]$ \\
\hline & $\mathrm{Ca}$ & $0.35[0.11-0.87]$ & $0.72[0.25-1.58]$ & $0.95[0.44-2.69]$ & 1.08 [0.59-3.45] \\
\hline & PTH & $1.36[0.48-2.97]$ & $1.42[0.72-2.99]$ & $1.92[0.68-3.88]$ & $1.39[0.22-2.49]$ \\
\hline & Sun exposure time & $1.34[0.21-2.54]$ & $1.21[0.61-2.35]$ & 2.59 [1.24-5.37] & $1.72[0.52-2.18]$ \\
\hline & Post-menopause & $1.17[0.58-2.77]$ & $2.26[1.46-4.21]$ & $2.36[0.79-6.41]$ & $1.91[1.03-3.35]$ \\
\hline & Childbearing $>3$ & $1.32[0.27-2.56]$ & $1.52[0.42-3.25]$ & $0.64[0.18-1.32]$ & $1.12[0.30-2.38]$ \\
\hline
\end{tabular}

Abbreviations: BMI, body mass index; Cl, confidence interval; OR, odds ratio; PTH, parathyroid hormone, Ca: Calcium (mg/dL), PTH: Parathyroid Hormone (pg/mL) Mantel-Haenszel statistic and multinomial logistic regression analysis were respectively utilized to compute OR $(95 \% \mathrm{Cl})$ for categorical and continuous variables Continuous variables were adjusted for age and serum levels of $25(\mathrm{OH}) \mathrm{D}$ as continuous variables, and categorical variables were adjusted for vitamin D deficiency and age using a variable with 2 categories $(<63 ; \geq 64)$.

There were insufficient female current smokers to run risk estimates.

cortical cataract, serum 25(OH)D level was significantly lower not only in women but also in men with nuclear opacities compared with control individuals prior to the adjustment for confounders (Tables 1 and 2). However, this significant difference did not persist in males after controlling for covariates (Table 4). The loss of significance after adjustment may be the reflection of the fact that serum 25(OH)D level and senile cataract are commonly correlated with some confounders, such as age, BMI, hypertension and sun exposure. Indeed, nuclear opacities among our male patients had significant associations with current smoking ( $\mathrm{OR}=1.70,95 \% \mathrm{CI}=1.17-3.96)$, BMI
$(\mathrm{OR}=1.55,95 \% \mathrm{CI}=1.03-3.18)$ and sun exposure time $(\mathrm{OR}=2.08,95 \% \mathrm{CI}=1.31-3.95)$ after adjustment for age and serum levels of vitamin D (Table 5). Meanwhile, the significant determinants of serum $25(\mathrm{OH}) \mathrm{D}$ concentration in males with NC were hypertension, PTH and age (Table 6). Although it has long been known that obesity is related to low 25(OH)D levels (33), a growing body of research has also been emerging to support the association between obesity and increased risk of cataract (8-9,25). In fact, it has been shown that greater adipose tissue results in more storage of vitamin D and thus lowers its circulating concentration (34), or that obesity may cause lens opacity 
Table 6. Multivariate regression analysis for serum 25(OH)D levels in different subtypes of age-related cataract according to gender

\begin{tabular}{|c|c|c|c|c|}
\hline & \multirow{2}{*}{ Types of age-related cataract } & \multirow{2}{*}{ Variable } & \multicolumn{2}{|c|}{ Multivariate analysis } \\
\hline & & & Correlation coefficient $(\beta)$ & $P$ value \\
\hline \multirow{11}{*}{ Men } & \multirow{3}{*}{ Pure nuclear } & Hypertension & 0.206 & $<0.001$ \\
\hline & & Age & 0.167 & 0.023 \\
\hline & & PTH & 0.141 & 0.041 \\
\hline & \multirow{2}{*}{ Pure cortical } & Daily Sun Exposure & 0.235 & $<0.001$ \\
\hline & & Age & 0.097 & 0.038 \\
\hline & \multirow{2}{*}{ Pure posterior sub-capsular } & Diabetes Mellitus & 0.169 & 0.002 \\
\hline & & BMI & 0.124 & 0.008 \\
\hline & \multirow{4}{*}{ Mixed } & Daily Sun Exposure & 0.176 & 0.012 \\
\hline & & Calcium & 0.127 & 0.022 \\
\hline & & Age & 0.118 & 0.035 \\
\hline & & Current smoking & 0.087 & 0.042 \\
\hline \multirow{9}{*}{ Women } & \multirow{2}{*}{ Pure nuclear } & Hypertension & 0.268 & $<0.001$ \\
\hline & & PTH & 0.113 & 0.036 \\
\hline & \multirow{3}{*}{ Pure cortical } & Age & 0.187 & $<0.001$ \\
\hline & & PTH & 0.157 & 0.008 \\
\hline & & Calcium & 0.103 & 0.037 \\
\hline & Pure posterior sub-capsular & Age & 0.202 & 0.002 \\
\hline & \multirow{3}{*}{ Mixed } & Daily Sun Exposure & 0.269 & $<0.001$ \\
\hline & & BMI & 0.136 & 0.027 \\
\hline & & PTH & 0.132 & 0.044 \\
\hline
\end{tabular}

Abbreviations: BMI, body mass index; Cl, confidence interval; OR, odds ratio; PTH, parathyroid hormone.

via oxidative stress and inflammation $(25,34)$. Moreover, lower concentration of $25(\mathrm{OH}) \mathrm{D}$ increased the risk of $\mathrm{NC}$ among our female patients as well (fully adjusted model $\mathrm{OR}=0.20,95 \% \mathrm{CI}=0.09-0.75, P=0.008$, Table 4 ), while higher education and elevated concentration of serum calcium contributed to a lower risk of nuclear opacity among them (Table 5). Vitamin D and PTH are major regulators of calcium homeostasis, which is crucial for the clarity of the lens. Indeed, calcium has long been known to play a role in the development of lens opacities; however its role in cataractogenesis is complex. Paradoxically, both hypocalcemia and hypercalcemia could result in cataracts and both have been found to be associated with experimental cataract models (27). Vitamin D and PTH levels are inversely correlated with each other, and both increase calcium concentration in blood. If these factors are associated with the risk of opacity development in lenses, it is possible that they may modify each other's impact on cataractogenesis risk. Thus, further studies with more detailed information- particularly regarding other predictors of serum calcium, PTH and vitamin D levelsare required. Besides, it must be noted that, consistent with other studies $(35,36)$, aging was also a major contributing factor to developing nuclear cataract for both genders in our investigation after controlling for serum $25(\mathrm{OH})$ levels $(\mathrm{OR}=1.85,95 \% \mathrm{CI}=1.22-3.96, P=0.034$ for men and $\mathrm{OR}$ $=2.06,95 \% \mathrm{CI}=1.41-4.16, P=0.019$ for women). In the case of female patients with nuclear opacity, hypertension and PTH were significantly correlated with serum levels of 25(OH)D (Table 5).
Controversial results have been obtained in association studies between serum concentrations of 25[OH]D and various subtypes of ARC. The first analysis in this regard was conducted by Jacques et al in 1988 (24). In this clinicbased case-control study, the relationship between a serum marker of vitamin D status (reflecting all sources of the molecule in the body) and ARC was investigated among 112 subjects aged 40-70 years. Their findings showed inverse associations for cortical opacity as well as for any cataract and blood vitamin D concentration (24). Interestingly, it was not until 2015 that the relationship between plasma levels of vitamin D and ARC attracted the attention of researchers again. In this year, the findings of two national surveys were published which had been conducted in the US (25) and South Korea (22). However, the findings of these research works were inconsistent. The American study investigated the relationship between serum concentrations of 25(OH)D and NC among 1278 participants of the Carotenoids in Age-Related Eye Disease Study (CAREDS), however failed to establish a significant association among the examined population who were indeed postmenopausal women aged 50 to 79 years. However, exploratory analysis suggested a protective influence of serum $25(\mathrm{OH}) \mathrm{D}$ on nuclear cataract development in women younger than 70 years (25). In the case of the Korean study, data from the fourth (2008 to 2009) and fifth (2010 to 2012) Korea National Health and Nutrition Examination Survey (KNHANES) was used by Jee and Kim to examine the association between serum concentrations of 25-hydroxyvitamin D and ARC 
(22). Their evaluation demonstrated that the OR for senile cataract decreased significantly in male, but not in female subjects, when the highest quintile of the serum $25(\mathrm{OH})$ $\mathrm{D}$ level was compared with the lowest quintile. They also found that as serum levels of $25(\mathrm{OH}) \mathrm{D}$ increased from the first (lowest) quintile to the fifth (highest) quintile, the ARC incidence increased proportionally in women but not in men (22). In another study which was conducted by Brown and Akaichi (27), at the same year, 2015, risk factors associated with PSC development were evaluated in 175 patients aged 51-70 years. Findings revealed that vitamin D deficiency was associated with PSC cataract. More recently, Park and Choi (26) re-evaluated KNHANES data using more strict inclusion criteria than Jee and Kim's study (22) and found increased levels of serum $25(\mathrm{OH})$ $\mathrm{D}$ were inversely associated with risk of nuclear cataract in 16086 adults (male and female) aged 40 years or older after adjustment for all possible confounders (26).

It is unclear why only females, and not males, with cortical or nuclear opacities, and not with mixed or PSC cataracts, had lower mean levels of $25(\mathrm{OH}) \mathrm{D}$ compared with controls in this study. However speculatively, it might be that the mechanism of action of vitamin $\mathrm{D}$ on ARC is different between genders as well as between different subtypes of ARC. Such sex- or subtype-related dissimilarities have already been observed in the study conducted by Jee and Kim (22). Further investigation is needed to identify factors contributing to this difference, particularly to clarify the precise sex-specific biologic mechanisms by which vitamin D inhibits the development of lens opacities.

Among different subtypes of ARC, the highest difference in serum $25(\mathrm{OH}) \mathrm{D}$ concentration was observed between men and women with cortical opacity (mean difference $=16.2 \mathrm{ng} / \mathrm{mL}$, Student's $t$ test, $P<0.001)$. Male patients afflicted with cortical cataract had even a marginally higher serum $25(\mathrm{OH}) \mathrm{D}$ concentration compared with control males (Table 1, Student's $t$ test, $P=0.061$ ). They also showed a significantly higher sun exposure time in comparison to women with pure cortical opacity (Student's $t$ test, $P<0.001$ ). Serum levels of 25(OH)D (fully adjusted model $\mathrm{OR}=0.25,95 \% \mathrm{CI}=0.12-0.96$, Table 4 ) and menopausal status (age- and vitamin D-adjusted $\mathrm{OR}=2.26,95 \% \mathrm{CI}=1.46-4.21$, Table 5 ) were the only predictors of pure cortical opacity among our female cases (Tables 4 and 5), whereas the significant determinants of pure cortical cataract among male patients included sun exposure time (age- and vitamin D-adjusted OR = 2.48, 95\% CI $=1.21-5.75$ ) and hypertension (age- and vitamin $\mathrm{D}$-adjusted $\mathrm{OR}=2.16,95 \% \mathrm{CI}=1.82-6.42$ ) (Table 5). Solar radiation was not among the significant determinants of cortical opacity among our female cases after adjustment for age and serum levels of $25(\mathrm{OH})$ D (Table 5). UV exposure has well been established as a cause for cortical opacity among the general population (14), however some investigations like the current one, failed to verify its relationship with CC in females (37). Besides, sun exposure time and age were identified as the variables accounting for the highest degree of variability in serum $25(\mathrm{OH}) \mathrm{D}$ among males and females with CC, respectively (Table 6). Unlike study of Jee and Kim (22), it seems that the cataractogenic effect of solar radiation on lenses outweighed its protective influences through vitamin D production in the skin among our male patients with cortical opacity. Men, compared with women, are usually involved in more activities outside the home and this exposes them to a greater sunlight exposure. On the other hand, women may more frequently use protective measures against solar UV exposure (e.g. sun block cream and clothes) which reduces vitamin $\mathrm{D}$ production in their skin.

The current investigation has several strengths. Measuring serum levels of $25(\mathrm{OH}) \mathrm{D}$ in a relatively large number of patients with ARC, robust inclusion criteria, and gender-stratified analysis were the main strengths of the present study. In addition, the current investigation has demonstrated the associations between serum concentration of vitamin D and different subtypes of ARC after adjustment for a broad range of socio-demographic and clinical factors. However, this investigation suffers from a number of limitations. First of all, some potential confounding variables such as female hormonal use, socioeconomic status, the use of sunscreen, and dietary habits were not examined in the current analysis. It is possible that the effect of these parameters might have masked the effect of association of serum 25-hydroxyvitamin D level with senile cataract. Second, the cross-sectional nature of the current investigation makes it difficult to be certain whether the measured vitamin D levels are true reflections of concentrations in the period before cataractogenesis. Third, as mentioned previously, serum concentration of $25(\mathrm{OH}) \mathrm{D}$ do not essentially reflect the aqueous humour concentration of vitamin D. Fifth, recall bias in estimating the average daily sun exposure time might be an issue in this study. However, the probability of this bias was likely to be the same in both patients and controls. Lastly, the case-control design can only show an association between exposure and outcome and does not provide information on causal relationships. Thus, our findings require further clarification from future prospective studies.

\section{Conclusion}

In conclusion, we found that serum levels of vitamin D in female patients with cortical or nuclear opacities are lower than control women. This is in accordance with the only study in the literature to our knowledge, which compared serum $25(\mathrm{OH}) \mathrm{D}$ levels in a sex-stratified manner (22). Those authors, like us here, reported that women, but not men, with ARC had lower serum concentration of $25(\mathrm{OH}) \mathrm{D}$ than those females who were not afflicted with senile cataracts. However, it must be noted that in the mentioned study all opacity types had been grouped 
into a single cataract category. Therefore, it is unclear whether D-vitamin concentration difference exists in all subtypes of ARC or in some of them. According to our results, increasing vitamin $\mathrm{D}$ levels in the body by supplementation, food fortification or sunlight exposure may possibly be helpful in preventing cataract formation, especially for the nuclear and cortical types in females. Of course, it must be seriously considered that several factors play a role in senile cataract, thus further studies with more related variables should be conducted to evaluate our results and to recognize other effective parameters. Nevertheless, the majority of the potential predictors of nuclear and cortical cataracts found in this study agree with results from previous investigations. Increased age, diabetes mellitus, hypertension, and current cigarette smoking, are risk factors that are generally consistent between various studies $(25,35-36)$.

\section{Limitations of the study}

One of the limitations of our study was the lack of cohort design to have a strong causality; it is recommended to conduct studies with follow-up approach.

\section{Authors' contribution}

NSA and QM conceived and designed the study; NSA, QM, and SMN acquired the data; NSA, QM, and SMN analyzed and interpreted the data; NSA and QM drafted the manuscript; NSA, QM, and SMN critically revised the manuscript for important intellectual content; all authors gave approval of the version to be submitted; all authors agree to be accountable for all aspects of the work.

Conflicts of interest

The authors declare that they have no competing interests.

\section{Ethical issues}

The research followed the tenets of the Declaration of Helsinki. The Ethics Committee of Urmia University of Medical Sciences approved this study. The institutional ethical committee at Urmia University of Medical Sciences approved all study protocols (IR. USMU.REC.1396.193). Accordingly, written informed consent was taken from all participants before any intervention. This study was extracted from M.D thesis of Sanaz Moradi Nahriq at this university (Thesis \#1395-01-63-2838). Moreover, ethical issues (including plagiarism, data fabrication, double publication) have been completely observed by the authors.

\section{Funding/Support}

We gratefully acknowledge all of the participants and the entire staff involved in this research. This study was extracted from Sanaz Moradi Nahriq medical thesis. Research deputy of Urmia University of Medical Sciences supported this study (Grant\# 899).

\section{References}

1. Cabot F, Saad A, McAlinden C, Haddad NM, Grise-Dulac A, Gatinel D. Objective assessment of crystalline lens opacity level by measuring ocular light scattering with a double-pass system. Am J Ophthalmol. 2013;155:629-635, 635.e1-2. doi: 10.1016/j.ajo.2012.11.005.

2. Stevens GA, White RA, Flaxman SR, Price H, Jonas JB, Keeffe $\mathrm{J}$, et al. Global prevalence of vision impairment and blindness: magnitude and temporal trends, 1990-2010. Ophthalmology 2013;120:2377-84. doi: 10.1016/j.ophtha.2013.05.025.
3. Vashist P, Talwar B, Gogoi M, Maraini G, Camparini M, Ravindran RD, et al. Prevalence of cataract in an older population in India: the India study of age-related eye disease. Ophthalmology. 2011;118:272-8.e1-2. doi: 10.1016/j. ophtha.2010.05.020.

4. Andley UP. Effects of alpha-crystallin on lens cell function and cataract pathology. Curr Mol Med 2009;9:887-892.

5. Hatch WV, Campbell Ede L, Bell CM, El-Defrawy SR, Campbell RJ. Projecting the growth of cataract surgery during the next 25 years. Arch Ophthalmol. 2012;130:1479-81. doi: 10.1001/ archophthalmol.2012.838.

6. Salm M, Belsky D, Sloan FA. Trends in cost of major eye diseases to Medicare, 1991 to 2000. Am J Ophthalmol. 2006;142:976-82. doi: 10.1016/j.ajo.2006.07.057.

7. Tan JS, Wang JJ, Younan C, Cumming RG, Rochtchina E, Mitchell P. Smoking and the long-term incidence of cataract: the Blue Mountains Eye Study. Ophthalmic Epidemiol. 2008;15:155-61. doi: 10.1080/09286580701840362.

8. Kuang TM, Tsai SY, Hsu WM, Cheng CY, Liu JH, Chou P. Body mass index and age-related cataract: the Shihpai Eye Study. Arch Ophthalmol 2005;123:1109-14.

9. Schaumberg DA, Glynn RJ, Christen WG, Hankinson SE, Hennekens $\mathrm{CH}$.. Relations of body fat distribution and height with cataract in men. Am J Clin Nutr 2000;72:1495-502.

10. Mares JA, Voland R, Adler R, Tinker L, Millen AE, Moeller SM, et al. Healthy diets and the subsequent prevalence of nuclear cataract in women. Arch Ophthalmol. 2010;128:738-49. doi: 10.1001/archophthalmol.2010.84.

11. Morris MS, Jacques PF, Hankinson SE, Chylack LT, Willett WC, Taylor A. Moderate alcoholic beverage intake and early nuclear and cortical lens opacities. Ophthalmic Epidemiol. 2004;11:53-65.

12. Williams PT. Prospective epidemiological cohort study of reduced risk for incident cataract with vigorous physical activity and cardiorespiratory fitness during a 7-year followup. Invest Ophthalmol Vis Sci. 2009;50:95-100.

13. Cedrone C, Culasso F, Cesareo M, Mancino R, Ricci F, Cupo $\mathrm{G}$, et al. Prevalence and incidence of age-related cataract in a population sample from Priverno, Italy. Ophthalmic Epidemiol. 1999;6:95-103. doi: 10.1076/opep.6.2.95.1562.

14. Taylor HR. Epidemiology of age-related cataract. Eye (Lond) 1999;13:445-448.

15. Mangge $\mathrm{H}$ et al. The role of vitamin $\mathrm{D}$ in atherosclerosis Inflammation Revisited: More a Bystander than a Player? Curr Vasc Pharmacol 2015;13:392-8.

16. Uberti F, Lattuada D, Morsanuto $V$, Nava U, Bolis G, Vacca $\mathrm{G}$, et al. Vitamin D protects human endothelial cells from oxidative stress through the autophagic and survival pathways. J Clin Endocrinol Metab. 2014;99:1367-74. doi: 10.1210/ jc.2013-2103.

17. Grant WB, Strange RC, Garland CF. Sunshine is good medicine. Sunshine is good medicine. The health benefits of ultraviolet- $B$ induced vitamin D production. J Cosmet Dermatol 2003;2:8698.

18. Yoo TK, Oh E, Hong S. Is vitamin D status associated with open-angle glaucoma? A cross-sectional study from South Korea. Public Health Nutr. 2014;17:833-43. doi: 10.1017/ S1368980013003492.

19. Choi JA, Han K, Park YM, La TY. Low serum 25-hydroxyvitamin $\mathrm{D}$ is associated with myopia in Korean adolescents. Invest Ophthalmol Vis Sci. 2014;55:2041-7. doi: 10.1167/IOVS.1312853.

20. Payne JF, Ray R, Watson DG, Delille C, Rimler E, Cleveland J, et al. Vitamin D insufficiency in diabetic retinopathy. Endocr Pract. 2012;18:185-93. doi: 10.4158/EP11147.

21. Parekh N, Chappell RJ, Millen AE, Albert DM, Mares JA. 
Association between vitamin $\mathrm{D}$ and age-related macular degeneration in the Third National Health and Nutrition Examination Survey, 1988 through 1994. Arch Ophthalmol. 2007;125:661-669.

22. Jee D, Kim EC. Association between serum 25-hydroxyvitamin D levels and age-related cataracts. J Cataract Refract Surg. 2015;41:1705-15.

23. Abdellah MM, Mohamed Mostafa E, Salama EH, Roshdy Mohamed E. Association of serum 25-hydroxyl vitamin D deficiency and age-related cataract: a casecontrol study. J Ophthalmol. 2019;2019:9312929. doi: 10.1155/2019/9312929.

24. Jacques PF, Hartz SC, Chylack LT Jr, McGandy RB, Sadowski JA. Nutritional status in persons with and without senile cataract: blood vitamin and mineral levels. Am J Clin Nutr. 1988;48:152-8. doi: 10.1093/ajcn/48.1.152.25.

25. 25. Rao P, Millen AE, Meyers KJ, Liu Z, Voland R, Sondel S, et al. The relationship between serum 25-hydroxyvitamin $D$ levels and Nuclear Cataract in the Carotenoid Age-Related Eye Study (CAREDS), an Ancillary Study of the Women's Health Initiative. Invest Ophthalmol Vis Sci 2015;56:4221-30. doi: 10.1167/iovs.15-16835.

26. Park S, Choi NK. Serum 25-hydroxyvitamin D and Age-Related Cataract. Ophthalmic Epidemiol 2017;24:281-286. doi: 10.1080/09286586.2017.1281427.

27. Brown CJ, Akaichi F. Vitamin D deficiency and posterior subcapsular cataract. Clin Ophthalmol 2015;9:1093-8. doi: 10.2147/OPTH.S84790.

28. Hagenau T, Vest R, Gissel TN, Poulsen CS, Erlandsen M, Mosekilde $\mathrm{L}$, et al. Global vitamin $\mathrm{D}$ levels in relation to age, gender, skin pigmentation and latitude: an ecologic meta- regression analysis. Osteoporos Int. 2009;20:133-40. doi: 10.1007/s00198-008-0626-y.

29. Reis AF, Hauache OM, Velho G. Vitamin D endocrine system and the genetic susceptibility to diabetes, obesity and vascular disease. A review of evidence. Diabetes Metab. 2005;31:31825

30. Chylack LT, Wolfe JK, Singer DM, Leske MC, Bullimore MA, Bailey IL, et al. The Lens opacities classification system III. The Longitudinal Study of Cataract Study Group. Arch Ophthalmol 1993;111:831-6.

31. Holick MF. Vitamin D deficiency. N Engl J Med. 2007;357:266281.

32. World Health Organization. Prevention and management of osteoporosis. World Health Organ Tech Rep Ser. 2003;921:164.

33. Vanlint S. Vitamin D and obesity. Nutrients 2013;5:949-956.

34. Vincent HK, Innes KE, Vincent KR. Oxidative stress and potential interventions to reduce oxidative stress in overweight and obesity. Diabetes Obes Metab. 2007;9:813-39. doi: 10.1111/j.1463-1326.2007.00692.x.

35. Delcourt C, Cristol JP, Tessier F, Leger CL, Michel F, Papoz L, et al. Risk factors for cortical, nuclear, and posterior subcapsular cataracts: the POLA study. Pathologies Oculaires Liees a I'Age. Am J Epidemiol. 2000;151:497-504.

36. Mukesh BN, Le A, Dimitrov PN, Ahmed S, Taylor HR, McCarty CA. Development of cataract and associated risk factors: the Visual Impairment Project. Arch Ophthalmol. 2006;124:7985.

37. Cruickshanks KJ, Klein BE, Klein R. Ultraviolet light exposure and lens opacities: the Beaver Dam Eye Study. Am J Public Health. 1992;82:1658-62. 